\title{
Mitochondrial ribosomal proteins: Candidate genes for mitochondrial disease
}

\author{
James E. Sylvester, $\mathrm{PhD}^{1}$, Nathan Fischel-Ghodsian, $\mathrm{MD}^{2}$, Edward B. Mougey, PhD' ${ }^{1}$, and Thomas W. O'Brien, PhD
}

\begin{abstract}
Most of the energy requirement for cell growth, differentiation, and development is met by the mitochondria in the form of ATP produced by the process of oxidative phosphorylation. Human mitochondrial DNA encodes a total of 13 proteins, all of which are essential for oxidative phosphorylation. The mRNAs for these proteins are translated on mitochondrial ribosomes. Recently, the genes for human mitochondrial ribosomal proteins (MRPs) have been identified. In this review, we summarize their refined chromosomal location. It is well known that mutations in the mitochondrial translation system, i.e., ribosomal RNA and transfer RNA cause various pathologies. In this review, we suggest possible associations between clinical conditions and MRPs based on coincidence of genetic map data and chromosomal location. These MRPs may be candidate genes for the clinical condition or may act as modifiers of existing known gene mutations (mt-tRNA, mt-rRNA, etc.). Genet Med 2004:6(2):73-80.
\end{abstract}

Key Words: mitochondrial, ribosomal proteins, oxidative phosphorylation, candidate genes, translation

Most of the energy requirements for cell growth, differentiation, and development are met by the mitochondrial ATP produced by the process of oxidative phosphorylation. Mitochondrial DNA encodes 13 essential proteins of this oxidative phosphorylation system. The mRNA for these proteins is translated on mitochondrial ribosomes. Interference with their synthesis, either by deletion or mutation of the mitochondrial genes for these proteins and other components of the mitochondrial translation system, such as mitochondrial tRNAs, is known to cause different mitochondrial diseases of variable severity, including myopathies and sensorineural disorders such as blindness and deafness. ${ }^{1}$ By analogy, loss or mutation of any of the 78 proteins required for function of the mitochondrial ribosome ${ }^{2}$ might also be expected to result in mitochondrial disease. Kenmochi et al. ${ }^{3}$ noted that some of the genes for mitochondrial ribosomal proteins (MRPs) do indeed map to chromosomal loci already associated with human disorders, such as deafness, retinitis pigmentosa, and Usher Syndrome $1 \mathrm{E}$. Now that sequence information is available for essentially all (78) of the human MRPs, and given recent advances in bioinformatics, it is possible to implicate deficiencies in several additional MRPs as candidates for mitochondrial disease.

\footnotetext{
From ${ }^{1}$ Nemours Children's Clinic, Jacksonville, Florida; ${ }^{2}$ Department of Pediatrics, CedarsSinai Medical Center, Los Angeles, California; and the ${ }^{3}$ Department of Biochemistry and Molecular Biology, Health Science Center, University of Florida, Gainesville, Florida.

James E. Sylvester, PhD, Nemours Children's Clinic, 807 Children's Way, Jacksonville, FL 32207.

Received: October 23, 2003.

Accepted: December 12, 2003.
}

DOI: 10.1097/01.GIM.0000117333.21213.17

\section{THE MITORIBOSOME}

Human cells contain two genomes and two protein synthesizing (translation) systems. The first is the nuclear genome of $3 \times 10^{9}$ bp that has 30,000 to 40,000 genes coding a much greater number of proteins whose mRNAs are translated by cytoplasmic ribosomes. The second genome is that found in a cytoplasmic organelle, the mitochondrion $(\mathrm{mt})$. It contains a circular DNA of $16,850 \mathrm{bp}$ (mtDNA) that codes for 2 rRNAs, 22 tRNAs, and 13 mRNAs. At least 1500 (3\%) nuclear gene products are translated on cytoplasmic ribosomes and imported by and function in the mitochondrion. ${ }^{4,5}$ The cytoplasmic ribosome consists of 4 rRNAs (28S, $18 \mathrm{~S}, 5.8 \mathrm{~S}$, and 5S) and 85 ribosomal proteins; the genes for these components are all mapped and reasonably well-studied. ${ }^{6}$ Mutations in genes of the cytoplasmic translation machinery (ribosome components plus many interacting factors) that cause various human diseases have been identified (see later). In contrast, genes from both genomes encode the components of the mitochondrion's ribosome. The mitochondrial rRNAs are encoded by mt DNA, whereas the ribosomal proteins are encoded in the nuclear genome, they are synthesized on cytoplasmic ribosomes, and then are imported into the mitochondria. There they assemble with the 2 rRNAs to form mitochondrial ribosomes, and they are responsible for translating the $13 \mathrm{mt}$ mRNAs. Unlike eukaryotic ribosomes and their bacterial ancestors, the mitochondrial ribosome is protein, not RNA, rich. For instance, approximately 7500 bases of rRNA exist in the human cytoplasmic ribosome compared to 2000 bases in the mitochondrial ribosome, whereas both have about 80 ribosomal proteins. A discussion of the evolutionary processes and its association with structure/function relationships of the ribosome is beyond the scope of this review, but see O'Brien 2002.7 


\section{MITOCHONDRIAL GENETICS}

The genes encoded in the nucleus are inherited in a Mendelian fashion, whereas the mitochondrial genome is exclusively maternally inherited, thus making mitochondrial genetics much more complicated. There exist many examples documenting loss of mitochondrial function due to mutations in both genomes and examples where nuclear gene variants can modify the phenotype exerted by a mutation in mt DNA.

Mutations in mitochondrial DNA, being much easier to identify, have been associated with many human diseases. ${ }^{8}$ The mutations can be either deletions of much DNA (Kearns-Sayre syndrome, for instance) or point mutations (Lebers Hereditary Optic Neuropathy, for instance); they can occur in every mtDNA of the individual (maternally inherited) or they can occur during replication in the somatic cell. Both of these processes can result in heteroplasmy (more than one type of mtDNA) and may or may not be limited to individual tissues. Because the mitochondria are responsible for energy production through oxidative phosphorylation (OXPHOS), cell types that depend on OXPHOS for a large part of their energy supply such as nerve, brain, heart, and muscle are particularly susceptible to mitochondrial malfunction. Each cell can contain hundreds of mitochondria, each with 2 to $10 \mathrm{mtDNAs}$; therefore, the degree of heteroplasmy may correlate with the threshold for onset and severity of disease in a tissue specific manner.

Mutations do occur in genes responsible for mitochondrial mRNA translation. The most common examples of mitochondrial disease caused by one of the 30 or so documented point mutations in mt tRNA are MELAS (myopathy, encephalopathy, lactic acidosis and recurrent stroke-like episodes) and MERRF (myoclonic epilepsy with ragged red fibers). Cardiac failure is the serious problem for MELAS patients. Tessa et al. ${ }^{9}$ reported cases of a few families in which each of the children had heart problems resulting in the death of one child from cardiac arrest at the age of 15 months. The others were diagnosed with dilated cardiomyopathy. Electron microscopic analysis of a skeletal muscle biopsy from one individual showed increased lipid droplets, subsarcolemmal mitochondrial aggregates, and giant mitochondria. Histochemistry revealed $10 \%$ cytochrome c oxidase-negative fibers. Lactate levels were normal. Sequencing of mitochondrial DNA detected a $\mathrm{T}$ to $\mathrm{C}$ nucleotide change at position 12297 in the $\mathrm{tRNA}^{\text {leu }}{ }^{9}$ Previously, cardiomyopathy has been associated with an A4269G mutation in tRNA ${ }^{\text {ile }}$ and a case of fatal infant cardiomyopathy with A4319G also in tRNA ${ }^{\text {ile }}{ }^{10}$ Also the A1555G mutation in the mt $12 \mathrm{~S}$ rRNA has been shown to be pathogenic in humans. This mutation appears usually in homoplasmic form and predisposes both to nonsyndromic and antibioticinduced deafness. Nonsyndromic deafness was initially identified in a large Arab-Israeli pedigree, and subsequently confirmed in populations around the world with the highest recognized frequency in Spain. ${ }^{1-13}$ Aminoglycoside ototoxicity is one of the most common causes of acquired deafness. Although vestibulocochlear damage is nearly universal when high drug levels are present for prolonged periods, at lower drug levels there appears to be a significant genetic component influencing susceptibility to aminoglycoside ototoxicity. This was demonstrated in 1993 by the analysis of three Chinese families in which several individuals developed deafness after the use of aminoglycosides. All three of these families had the A1555G mutation in the $12 \mathrm{~S}$ ribosomal RNA gene, whereas the mutation was not seen in hundreds of controls. ${ }^{11}$ This finding was confirmed subsequently in multiple populations around the world. ${ }^{13}$

It appears that the mitochondrial dysfunction induced by the $\mathrm{A} 1555 \mathrm{G}$ mutation is primarily a decrease in mitochondrial protein synthesis affecting all proteins similarly. ${ }^{14}$ Importantly, the percentage decrease of protein synthesis when compared to ethnically matched cell lines without the mtDNA mutation varies with the clinical status of the individual who provided the cell line. For instance, cell lines from hearing impaired individuals showed an average decrease of $48 \%$ in protein synthesis, whereas cell lines from their hearing siblings showed an average decrease of $28 \%$. Similarly, cell lines from deaf individuals also showed more significant decreases in oxygen consumption, and enzymatic activity of OXPHOS complexes I, III, and IV, when compared to cell lines from their unaffected siblings. ${ }^{14}$ More recently, this nuclear effect was demonstrated independently by transferring mitochondria from deaf and hearing individuals with the A1555G mutation and those without the mutation into human cells which do not contain any mitochondrial DNA ( $\rho^{\mathrm{o}} 206$ cells). With this constant nuclear background, mitochondria containing the A1555G mutation showed significant decreases in the rates of growth in galactose medium, mitochondrial protein synthesis, total oxygen consumption, and complex I-, III-, and IV-dependent respiration, with no significant differences between mitochondria obtained from deaf or from hearing individuals. ${ }^{15}$ Because the A1555G mutation in the mitochondrial $12 \mathrm{~S}$ rRNA gene accounts only for $17 \%$ to $33 \%$ of patients with aminoglycoside ototoxicity, it appeared possible that other susceptibility mutations can be found in the same gene. DNA from 35 Chinese sporadic patients with aminoglycoside ototoxicity and without the A1555G mutation was analyzed for sequence variations in the $12 \mathrm{~S}$ rRNA gene. One sequence change, an absence of a thymidine at position 961 with varying numbers of cytosines inserted ( $\delta$ T961insCn), appeared likely to be a pathogenic mutation. ${ }^{16}$ More recently, an Italian family with 5 maternally related members who all became deaf after aminoglycoside treatment were found to have the same $\delta$ T961insCn mutation. ${ }^{17}$ This sequence change was not found in 799 control individuals, ${ }^{16}$ but Tang et al. ${ }^{18}$ found the mutation in 7 out of 1173 random neonatal dried blood spot cards. The real population frequency of this mutation remains thus undetermined, and the existing data are therefore not conclusive on whether this mutation is pathogenic.

An experimentally artificial situation is also very illustrative. The Wallace Lab ${ }^{19}$ engineered a mouse cybrid carrying a mitochondrial DNA mutation. Briefly, mouse embryonic stem (ES) cells were depleted of their mitochondria by growing them in Rhodamine-66. New mitochondrial DNA was introduced 
such that nuclear DNA and mtDNA originated from different sources (cybrid). Mitochondrial DNA with a mutation at nucleotide position 2443 of the $16 \mathrm{~S}$ rRNA gene was introduced, the ES cells transferred into a pseudopregnant foster mother, and highly chimeric offspring generated. These offspring had congenital cataracts and functional abnormalities in the retina on electroretinopathy. When these mice were mated, the pups either died in utero or in the very early neonatal period with severe growth retardation and with dilated cardiomyopathy. Large atypical mitochondria were found in both the skeletal and heart muscle tissues. Not surprising, the loss of mitochondrial protein translation was lethal and due to abnormal heart development.

Mutations in nuclear genes, which impact on mitochondrial function, will present as autosomal (or sex-linked) dominant or recessive traits. Obvious examples are those genes that are important for the fidelity of mtDNA replication, repair, or propagation during development. A second example of metabolic disorders would be mutations in those genes coding for proteins that are members of the Tricarbocylic acid (TCA or Krebs cycle) or subunits of the respiratory chain complexes. Other examples include MnSOD (superoxide dismutase)20 and Frataxin, ${ }^{21}$ which appear to protect against oxidative damage to mitochondria by eliminating free radicals and properly regulating iron levels, respectively. ${ }^{22,23}$ In fact, mutations may occur in any of the nuclear genes that code for proteins destined to act in or on the mitochondrion. ${ }^{24,25}$ Mutations in factors involved in mitochondrial translation have been implicated in age-related respiratory deficiencies. ${ }^{26}$ Candidates include genes for aminoacyl-tRNA synthetases, and initiation, elongation, and termination factors for mitochondrial translation. Mutations in yeast MTG1, a protein suggested to be involved in mitochondrial ribosome assembly and thus required for mitochondrial translation ${ }^{27}$ compromises mitochondrial protein synthesis, leading to diminished capacity for oxidative phosphorylation and ensuing mitochondrial disease. A human gene homologue, hMTG1, is located at chromosome 10q26.3; however, no known genetic disorders presently map to that position.

\section{RIBOSOMAL PROTEIN DISEASES}

In humans, very few diseases have been identified that are caused by defective or aberrantly expressed ribosomal proteins. This is perhaps not surprising because a strong argument could be made for the lethality of such conditions. The beststudied example of a ribosomal protein disease is DiamondBlackfan anemia (DBA). First reported in the late $1930 \mathrm{~s},{ }^{28}$ DBA is a rare congenital hypoplastic anemia with a prevalence of 4 to 7 cases per million births, ${ }^{29-32}$ and is characterized by absent or decreased erythroid precursors. ${ }^{33}$ Frequently, DBA is accompanied by physical defects $(41 \%, N=399), 29,30,34,35$ including head and face abnormalities ( $8-52 \%)$, thumb abnormalities (9-18\%), and short stature (22\%). Although most cases of DBA are sporadic (approximately 75\%), both dominant and autosomal recessive patterns of inheritance have been impli- cated in the remaining $25 \%$ of cases ${ }^{30,36-38}$ with dominant inheritance being more common. ${ }^{39}$

In 1997, Gustavsson et al., ${ }^{39}$ examined chromosome 19 for linkage to DBA after identifying a DBA patient with a balanced reciprocal translocation $(\mathrm{X} ; 19)(\mathrm{p} 21 ; \mathrm{q} 13) .{ }^{39}$ (The X chromosome was excluded from consideration based on the observed autosomal transmission of DBA.) Subsequently, the region surrounding the $(\mathrm{X} ; 19)(\mathrm{p} 21 ; \mathrm{q} 13)$ translocation break point was cloned and sequenced allowing the identification of cytoplasmic ribosomal protein S19 (RPS19) as the gene disrupted by the translocation..$^{40}$ RPS19 is a component of the small subunit of the cytoplasmic ribosome where it has roles in both the structure of the subunit and in binding of elongation factor $2 .{ }^{41}$ Additionally, RPS19 homodimers released from the cell function as chemotactic factors for monocytes during macrophagedependent apoptotic cell clearance. ${ }^{42}$

Further studies have identified RPS19 mutations in 20\% to $25 \%$ of both sporadic and unrelated familial DBA patients ${ }^{30,40,43}$ (reviewed in Da Costa et al. ${ }^{44}$ ). In all patients examined, only a single allele of RPS19 has been mutated, suggesting that at least one healthy RPS19 allele is required for viability. ${ }^{30,40,43}$ Interestingly, there appears to be little genotype-phenotype correlation between the type of RPS19 mutation and the clinical presentation of DBA or its associated physical anomalies. For example, in a pair of monozygotic twins who present with DBA, share the same RPS19 mutation, and are presumably genetically identical, only one exhibited thumb duplication, whereas their father who contributed the RPS19 missense mutation was healthy except for persistent macrocytosis. ${ }^{30}$

Because mutations in RPS19 are found in only 20\% to $25 \%$ of all DBA patients, a great deal of effort has been made to identify other candidate genes. In one such study, Gazda et al. ${ }^{45}$ analyzed 14 multiplex families in a genome wide search for linkage to DBA and identified a linked loci on chromosome 8. In the same study, they further refined their data by analyzing 38 families with polymorphic markers to chromosome 8 . In total, 18 of 38 families were consistent with linkage to chromosome 8 , in a region flanked by D8S518 and D8S1825. Interestingly, none of the known ribosomal proteins for which sequence data are available (cytoplasmic or mitochondrial) map to this loci.

\section{MRP CHARACTERIZATION, GENE IDENTIFICATION, AND MAPPING}

Analysis of mammalian MRPs by 2D PAGE revealed that mammalian mitochondrial ribosomes contain many more proteins, of vastly different properties, than bacterial ribosomes, ${ }^{46}$ and that they are evolving more rapidly than proteins in bacterial or eukaryotic cytoplasmic ribosomes. ${ }^{47}$ Early efforts (in the "pregenomic era") to identify coding sequences for mammalian MRPs involved the labor-intensive screening of cDNA libraries with antibodies prepared against individual MRPs or with degenerate oligonucleotides designed from limited amino acid sequence information derived from individual 
Table 1

Location of genes for the proteins of the large mitochondrial ribosomal subunit and map positions for candidate associated disorders

\begin{tabular}{|c|c|c|c|}
\hline \multicolumn{2}{|c|}{ Human $M R P L$ gene locations } & \multirow[b]{2}{*}{ Candidate disorder } & \multirow[b]{2}{*}{ Map posi } \\
\hline Protein & Location & & \\
\hline MRPL1 & $4 \mathrm{q} 21.1^{a, b, c, d}$ & & \\
\hline MRPL2 & $6 \mathrm{p} 21.3^{a}-6 \mathrm{p} 21.1^{b, c, d}$ & $\mathrm{SCABD}^{e}$ & $6 \mathrm{p} 23-\mathrm{p} 21$ \\
\hline \multirow[t]{3}{*}{ MRPL3 } & $3 \mathrm{q} 22.1^{b, c, d}$ & DFNA1 $8^{f}$ & $3 q 22$ \\
\hline & & Moebius syndrome 2 & $3 q 21-q 22$ \\
\hline & & DFNB15 $5^{g}$ (digenic) & $3 q 21.3-q 2$ \\
\hline MRPL4 & $19 \mathrm{p} 13.2^{a, b, c, d}$ & $\mathrm{DFNB}_{15}{ }^{g}$ (digenic) & $19 \mathrm{p} 13.3-\mathrm{p}$ \\
\hline MRPL9 & $1 \mathrm{q} 21^{a}-\mathrm{q} 21.3^{c, d}$ & DFNA $7^{f}$ diabetes & $1 \mathrm{q} 21-\mathrm{q} 23$ \\
\hline MRPL10 & $17 \mathrm{q} 21.3^{a}-17 \mathrm{q} 21.32^{c, d}$ & & \\
\hline MRPL11 & $11 \mathrm{q} 13.3^{a}-\mathrm{q} 13.32^{c}$ & & \\
\hline MRPL12 & $17 \mathrm{q} 25^{a}-17 \mathrm{q} 25.3^{c}$ & DFNA2 $0^{f} \mathrm{NABP}^{h}$ & $17 \mathrm{q} 25.3$ \\
\hline MRPL13 & $8 \mathrm{q} 22.1-\mathrm{q} 22.3^{a}, 8 \mathrm{q} 24.12^{b, c, d}$ & & \\
\hline MRPL14 & $6 \mathrm{p} 21.3^{a}-\mathrm{p} 21.1^{\mathrm{c} d}$ & $\mathrm{SCABD}^{e}$ & $6 \mathrm{p} 23-\mathrm{p} 21$ \\
\hline MRPL15 & $8 \mathrm{q} 11.2^{a, b}-8 \mathrm{q} 11.23^{c, d}$ & & \\
\hline MRPL16 & $11 \mathrm{q} 12^{a, b}-\mathrm{q} 13.1^{a}$ & & \\
\hline MRPL17 & $11 \mathrm{p} 15.5^{a}-15.4^{a, c, d}$ & & \\
\hline MRPL18 & $6 \mathrm{q} 25.3^{b, d}-6 \mathrm{q} 26^{c}$ & & \\
\hline MRPL19 & $2 \mathrm{p} 11.2-\mathrm{q} 11.2^{a}, 2 \mathrm{p} 12^{c, d}$ & DFNA43 $3^{f}$ & $2 \mathrm{p} 12$ \\
\hline MRPL20 & $1 \mathrm{p} 36.3^{a, d}-\mathrm{p} 36.2^{a, b}$ & $\begin{array}{l}\text { Parkinson disease } 6 \\
\text { cataract }\end{array}$ & $\begin{array}{l}1 \mathrm{p} 36-\mathrm{p} 35 \\
1 \mathrm{p} 36\end{array}$ \\
\hline
\end{tabular}

MRPL21 11q13.1 ${ }^{b}$

MRPL22 5q33. ${ }^{a}-\mathrm{q} 33.2^{a, c, d}$

MRPL23 11p15.5 $5^{a, c, d}-15.4^{a, b}$

MRPL24 1q21 ${ }^{a}-\mathrm{q} 22^{a, b}, 1 \mathrm{q} 23.1^{d}$

DFNA7 $^{f}$

$11 \mathrm{p} 15.5$

MRPL27 17q21.3-q22 $2^{a, b}, \mathrm{q} 21.33^{c, d}$

diabetes

MRPL28 $16 \mathrm{p} 13.3^{b, c, d}$

MRPL30 2q11.2 $2^{a, b, c, d}$

MRPL32 7p14a,b,d

MRPL33 2p23.2 $2^{b, c}-\mathrm{p} 21^{a}$

MRPL34 19p13.1 $1^{a, b}, \mathrm{p} 13.12^{d}$

MRPL35 2p11.2 $2^{b, c, d}$

MRPL36 5p15.3 $3^{a, b, d}$

MRPL37 1p32.3 $3^{c, d}, 1 \mathrm{p} 32.1^{a, b}$
MRPL38 17q25.1 $1^{c, d}-\mathrm{q} 25.3^{b}$

MRPL39 21q21.3 $3^{b, c, d}$

MRPL40 22q11.1 ${ }^{d}-\mathrm{q} 11.2^{a, b}$

MRPL41 9q34.3 $3^{a, b, c, d}$

Parkinson disease $\quad 1 \mathrm{p} 32$ 10

$\begin{array}{ll}\text { DFNA20f } & 17 \mathrm{q} 25.3 \\ \mathrm{NABP}^{h} & \end{array}$

Usher syndrome 1E 21q21

DiGeorge syndrome 22q11

Joubert syndrome $9 \mathrm{q} 34.3$

DNFB33 $^{g} \quad 9 q 34.3$

Leigh Syndrome $\quad 9 \mathrm{q} 34$

$\begin{array}{lll}\text { MRPL42 12q22 } & \text { DFNA25 } & \text { 12q21-24 }\end{array}$
Table 1

Continued

\begin{tabular}{|c|c|c|c|}
\hline \multicolumn{2}{|c|}{ Human $M R P L$ gene locations } & \multirow[b]{2}{*}{ Candidate disorder } & \multirow[b]{2}{*}{ Map position } \\
\hline Protein & Location & & \\
\hline MRPL43 & $10 \mathrm{q} 24^{1}-\mathrm{q} 24.3^{a, b, c, d}$ & Alzheimer disease 6 & $10 \mathrm{q} 24$ \\
\hline MRPL44 & $2 \mathrm{q} 36.1^{b, c, d}$ & & \\
\hline MRPL45 & $17 \mathrm{q} 12^{b, c, d}-\mathrm{q} 21.2^{b}$ & diabetes & $17 \mathrm{p} 11.2-\mathrm{q} 22$ \\
\hline MRPL46 & $15 \mathrm{q} 25.3^{b, c, d}$ & DFNA30 $f$ & $15 q 25-q 26$ \\
\hline MRPL47 & $3 \mathrm{q} 26.32^{d}-3 \mathrm{q} 27.1^{b}$ & Spastic paraplegia 14 & $3 \mathrm{q} 27-\mathrm{q} 28$ \\
\hline MRPL48 & $11 \mathrm{q} 13.2-\mathrm{q} 13.3^{b}, \mathrm{q} 13.4^{c, d}$ & Leigh syndrome & $11 \mathrm{q} 13$ \\
\hline MRPL49 & $11 \mathrm{q} 13.1^{b, c, d}$ & Leigh syndrome & $11 \mathrm{q} 13$ \\
\hline MRPL50 & $9 \mathrm{q} 31.1^{b, d}$ & & \\
\hline MRPL51 & $12 \mathrm{p} 13.31^{b, c, d}$ & & \\
\hline MRPL52 & $14 \mathrm{q} 11.1^{b}-\mathrm{q} 11.2^{d}$ & & \\
\hline MRPL53 & $2 \mathrm{p} 13.1^{c, d}-\mathrm{p} 12^{b}$ & $\begin{array}{l}\text { MMDFS }^{i} \\
\text { Parkinson disease } 3 \\
\text { DFNA43 } 3^{f}\end{array}$ & $\begin{array}{l}2 \mathrm{p} 14-2 \mathrm{p} 13 \\
2 \mathrm{p} 13 \\
2 \mathrm{p} 12\end{array}$ \\
\hline MRPL54 & $19 \mathrm{p} 13.3^{b, c}$ & $\begin{array}{l}\text { Vacuolar } \\
\text { neuromyopathy } \\
\text { Leigh syndrome } \\
\text { DFNB15 }^{g}\end{array}$ & $\begin{array}{l}19 \mathrm{p} 13.3 \\
19 \mathrm{p} 13.3 \\
19 \mathrm{p} 13.3-\mathrm{p} 13.1\end{array}$ \\
\hline MRPL55 & $1 \mathrm{q} 42.13^{b, d}$ & & \\
\hline MRPL56 & $15 \mathrm{q} 22.1^{b}-\mathrm{q} 22.2^{d}$ & & \\
\hline $\begin{array}{l}{ }^{a} \text { STS-cyto } \\
{ }^{b} \text { NCBI Hu } \\
\text { genome/se } \\
{ }^{c} \text { Human } \\
\text { genome.u } \\
{ }^{d} \text { Rebhan e } \\
{ }^{e} \text { SCABD S } \\
{ }^{\circ} \text { DFNA De } \\
{ }^{g} \text { DFNB De } \\
{ }^{g} \text { Neuritis, } \\
{ }^{i} \text { MMDFS }\end{array}$ & $\begin{array}{l}\text { genic mapping. } \\
\text { aman genome resources, } \\
\text { eq/HsBlast.html). } \\
\text { Genome Browser Gateway } \\
\text { csc.edu/cgi-bin/hgGateway? } \\
\text { t al. }{ }^{39} \text { http://bioinformatics } \\
\text { pinocerebellar ataxia with } \\
\text { eafness, autosomal dominan } \\
\text { eafness, autosomal recessive } \\
\text { with brachial predilection } \\
\text { Multiple mitochondrial dys }\end{array}$ & $\begin{array}{l}\text { ld } 33 \text { (http://www.nct } \\
\text { t UCSC (April } 2003 \\
\text { g=human } \\
\text { eizmann.ac.il/cards } \\
\text { ndness and deafness } \\
\text { nonsyndromic sensorir }\end{array}$ & $\begin{array}{l}\text { bi.nlm.nih.gov/ } \\
\text { freeze) http:// }\end{array}$ \\
\hline
\end{tabular}

MRPs. With the advent of the Human Genome Project, and the ensuing flood of expressed sequence information in the databases, it was no longer necessary to isolate MRP cDNA clones for sequence analysis. It was occasionally possible to identify MRP sequences by virtue of their homology to known bacterial ribosomal proteins. However, because the "extra" proteins in mammalian mitochondrial ribosomes have no counterpart in either bacterial or cytoplasmic ribosomes, ${ }^{7}$ it was still necessary to obtain amino acid sequence information for each of the MRPs in ribosomes isolated from rat or bovine liver mitochondria. Amino acid sequence information from mammalian mitochondrial ribosomes can be used to identify human MRP coding sequences in the databases, using BLAST (TBLASTN) searches of the nonredundant and EST databases. The recent use of proteomic approaches for sequence analysis of MRPs accelerated the process, and we now have sequences for essentially all (78) of the human MRPs.

Recent advances in bioinformatics and the continuing refinement of the Human Genome Map improve the mapping precision over what was possible with experimental probe hy- 
Table 2

Location of genes for the proteins of the small mitochondrial ribosomal subunit and map positions for candidate associated disorders

\begin{tabular}{|c|c|c|c|}
\hline \multicolumn{2}{|c|}{ Human MRPS gene locations } & \multirow[b]{2}{*}{ Candidate disorder } & \multirow[b]{2}{*}{ Map position } \\
\hline Protein & Location & & \\
\hline MRPS2 & $9 \mathrm{q} 34.3^{a, b, c, d}$ & $\begin{array}{l}\text { DNFB33 }^{j} \\
\text { Joubert syndrome } \\
\text { Leigh syndrome }\end{array}$ & $\begin{array}{l}9 \mathrm{q} 34.3 \\
9 \mathrm{q} 34.3 \\
9 \mathrm{q} 34\end{array}$ \\
\hline MRPS5 & $2 \mathrm{q} 11.1^{b, c, d}$ & & \\
\hline MRPS6 & $21 \mathrm{q} 21.3^{a}-\mathrm{q} 22.1^{a, c, d}$ & & $21 \mathrm{q} 22 / 21 \mathrm{q} 22.3$ \\
\hline MRPS7 & $17 \mathrm{q} 25.1^{c, d}-\mathrm{q} 25.2^{b}$ & $\mathrm{NAPB}^{k}$ & $17 \mathrm{q} 25$ \\
\hline MRPS9 & $2 \mathrm{q} 12.1^{b}$ & & \\
\hline MRPS10 & $6 \mathrm{p} 21.1^{b, c, d}$ & $\mathrm{SCABD}^{l}$ & $6 \mathrm{p} 23-\mathrm{p} 21$ \\
\hline MRPS11 & $15 \mathrm{q} 25^{a}-\mathrm{q} 25.3^{b, c, d}$ & DFNA30 $0^{m}$ & $15 q 25-q 26$ \\
\hline MRPS12 & $19 \mathrm{q} 13.11^{a}-\mathrm{q} 13.2^{a, b, c, d}$ & DFNA4 $^{m}$ & $19 q 13$ \\
\hline MRPS14 & $1 \mathrm{q} 24^{a, b}-\mathrm{q} 25.1^{a, b, c, d}$ & DFNM $1^{n}$ of DFNB $26^{j}$ & $1 \mathrm{q} 24$ \\
\hline MRPS15 & $1 \mathrm{p} 34.3^{b, c, d}$ & $\begin{array}{l}\text { DFNA2 } 2^{13}, 3^{\text {rd }} \text { gene; Stuve- } \\
\text { Wiedemann syndrome }\end{array}$ & $1 \mathrm{p} 34$ \\
\hline MRPS16 & $10 \mathrm{q} 22.1^{a, b}-\mathrm{q} 22.2^{d}$ & & \\
\hline MRPS17 & $7 \mathrm{p} 11.2^{b, c, d}$ & Russell-Silver Syndrome & $7 \mathrm{p} 11.2$ \\
\hline MRPS18A & $6 \mathrm{p} 21.1^{b, c, d}-6 \mathrm{p} 21.3^{a}$ & $\mathrm{SCABD}^{l}$ & $6 \mathrm{p} 23-\mathrm{p} 21$ \\
\hline MRPS18B & $6 \mathrm{p} 21.3^{b, d}$ & $\mathrm{SCABD}^{l}$ & $6 \mathrm{p} 23-\mathrm{p} 21$ \\
\hline MRPS18C & $4 \mathrm{q} 21.23^{b, c, d}$ & & \\
\hline MRPS21 & $1 \mathrm{q} 21.2^{a, b, c, d}$ & DFNA7 $7^{m}$ & $1 \mathrm{q} 21-\mathrm{q} 23$ \\
\hline MRPS22 & $3 \mathrm{q} 23^{a, b, c, d}$ & cataract & $3 q 21-q 25$ \\
\hline MRPS23 & $17 \mathrm{q} 23^{b}-\mathrm{q} 23.2^{d}$ & $\begin{array}{l}\text { Alzheimer Disease } \\
\text { Russell-Silver Syndrome }\end{array}$ & $\begin{array}{l}17 \mathrm{q} 23 \\
17 \mathrm{q} 23-\mathrm{q} 24\end{array}$ \\
\hline MRPS24 & $7 \mathrm{p} 14^{a, b}-7 \mathrm{p} 13^{c}$ & & \\
\hline MRPS25 & $3 \mathrm{p} 25.1^{a, b, c, d}$ & Cardiomyopathy, dilated, $1 \mathrm{E}$ & $3 \mathrm{p} 25-\mathrm{p} 22$ \\
\hline MRPS26 & $20 \mathrm{p} 13^{a, b, c, d}$ & $\mathrm{CDPD}^{\circ}$ & $20 \mathrm{p} 13$ \\
\hline MRPS27 & $5 \mathrm{q} 13.1^{b}-\mathrm{q} 13.2^{c, d}$ & & \\
\hline MRPS28 & $8 \mathrm{q} 21.1-\mathrm{q} 21.2^{a, b}$ & & \\
\hline MRPS29 & $1 \mathrm{q} 21^{a, b}-\mathrm{q} 22^{a, b, d}$ & DFNA7 ${ }^{m}$ migraine & $1 \mathrm{q} 21-\mathrm{q} 23$ \\
\hline MRPS30 & $5 \mathrm{p} 12^{a, d}-5 \mathrm{q} 11^{a, b}$ & Leigh syndrome & $5 q 11$ \\
\hline MRPS31 & $13 \mathrm{q} 13.3^{b}-\mathrm{q} 14.11^{d}$ & moebius syndrome 1 & $13 \mathrm{q} 12.2-\mathrm{q} 13$ \\
\hline MRPS33 & $7 \mathrm{q} 34^{b, c, d}$ & DFNB13 ${ }^{j}$ & $7 q 34-q 36$ \\
\hline MRPS34 & $16 \mathrm{p} 13.3^{d}-16 \mathrm{p} 13.13^{c, d}$ & & \\
\hline MRPS35 & $12 \mathrm{p} 11^{b}-\mathrm{p} 11.2^{c, d}$ & $\begin{array}{l}\text { Parkinson disease } 8 \\
\text { Alzheimer disease } 5 \\
\text { Complex } 1 \text { deficiency }\end{array}$ & $\begin{array}{l}\text { 12p11.2-q13.1 } \\
12 \mathrm{p} 11.23-\mathrm{q} 13.12\end{array}$ \\
\hline MRPS36 & $5 \mathrm{q} 12.3^{b}-\mathrm{q} 13.2^{c, d}$ & & \\
\hline
\end{tabular}

${ }^{{ }^{a}}$ STS-cytogenic mapping. ${ }^{3}$

${ }^{b}$ NCBI Human genome resources, Build 33 (http://www.ncbi.nlm.nih.gov/genome/seq/HsBlast.html)

${ }^{c}$ Human Genome Browser Gateway at UCSC (April 2003 freeze) http://genome.ucsc.edu/cgi-bin/hgGateway?org=human

${ }^{d}$ Rebhan et al. ${ }^{69} \mathrm{http}: / /$ bioinformatics.weizmann.ac.il/cards

${ }^{j}$ DFNB Deafness, autosomal recessive.

${ }^{k}$ Neuritis, with brachial predilection.

${ }^{l}$ Spinocerebellar ataxia with blindness and deafness.

${ }^{m}$ DFNA Deafness, autosomal dominant nonsyndromic sensorineural.

${ }^{n}$ Deafness, nonsyndromic, modifier 1.

${ }^{\circ}$ Corneal dystrophy and perceptive deafness 1 . 
bridization techniques. Gene map loci have been determined for all 78 human MRPs (Tables 1 and 2). Many of the MRPs map to loci associated with various developmental and sensorineural disorders. The consequences of mutations in MRPs are expected to range from lethality to marginally impaired energy metabolism. Mutations (or absence) of ribosome assembly proteins or other essential proteins, such as MRPL12, may be lethal due to the absence or inadequate amounts of functional mitochondrial ribosomes. MRPL12 is the initial binding site for elongation factors on the mitochondrial ribosome. Mutations of this protein may so impair ribosome function that products of mitochondrial protein synthesis are insufficient to maintain even a basal metabolic rate. Mutations that do not fully inactivate protein function may have intermediate, "crippling" effects, resulting in diminished oxidative phosphorylation capacity, with attendant growth and developmental anomalies. Mutations may also manifest in a tissuespecific manner, depending on special energy demands, resulting in neuropathies, myopathies, and developmental and sensorineural disorders. Mutations in tissue-specific MRP isoforms ${ }^{48}$ may also impact selected tissues, giving rise to a spectrum of disorders. ${ }^{1}$

As inferred earlier, mitochondrial disorders can manifest in various phenotypic classifications. We see in Tables 1 and 2 that MRP genes are candidates for dwarfism, growth retardation, and limb deformity disorders such as Russell-Silver Syndrome, ${ }^{49,50}$ Stuve-Wiedemann Syndrome, ${ }^{51}$ and Moebius Syndrome I. ${ }^{52}$ Metabolic disorders for which MRP genes associate by map position are Multiple Mitochondrial Dysfunctions, ${ }^{53}$ Stuve-Wiedemann Syndrome, ${ }^{51}$ Leigh Syndrome, ${ }^{54}$ and diabetes. Candidate eye and ear disorders include Corneal Dystrophy and Perceptive Deafness, ${ }^{55}$ Spinocerebellar Ataxia with blindness and deafness, Moebius Syndrome I, ${ }^{52}$ Usher Syndrome, Type 1E, ${ }^{56}$ DiGeorge Syndrome, ${ }^{57}$ and nonsyndromic hearing losses (15 dominant and 7 autosomal recessive). Failure to maintain adequate ATP levels in cochlear hair cells, in the face of diminished oxidative phosphorylation capacity, may trigger mitochondrial apoptosis or necrosis in some or all of the stimulated hair cells, resulting in hearing loss. In this respect, it may not be surprising that many of the MRPs map to loci associated with nonsyndromic hearing loss. Cardiac disorders for which there may be a mitochondrial involvement are Dilated Cardiomyopathy, Dilated, 1E, ${ }^{58}$ and DiGeorge Syndrome. ${ }^{57}$ Muscle, nerve, and dementia disorders with mitochondrial involvement include Neuritis with Brachial Predilection, ${ }^{59}$ spinocerebellar ataxia, Alzheimer Disease (AD), Parkinson disease, Spastic paraplegia $14,{ }^{60}$ and Vacuolar neuromyopathy. ${ }^{61}$ Alzheimer disease and Parkinson disease has been included in our listing because susceptibility to these diseases has been associated with defects in mitochondrial DNA. ${ }^{62,63}$ Similarly, there is a form of a maternally transmitted diabetes, with reduced mitochondrial protein synthesis in patients harboring a mitochondrial DNA deletion. ${ }^{64}$ The association of reduced mitochondrial energy metabolism with susceptibility to diabetes is strengthened by the development of diabetes with reduced expression of the genes for mitochondrial energy metabolism. ${ }^{5}$

\section{THERAPIES FOR OXIDATIVE PHOSPHORYLATION DISORDERS}

There is no cure for disorders of oxidative phosphorylation. The best evidence for therapeutic benefit exists for exercise. Endurance training increases capillarization of muscle and the density of mitochondria in individual cells, whereas resistance training recruits satellite muscle cells into an active state of energy production. ${ }^{66}$ In addition, a variety of drugs and dietary supplements have been used in attempts to treat, or at least modulate the course of OXPHOS disorders. In a select group of patients deficient in coenzyme Q10, replacement of coenzyme Q10 or its synthetic analogue idebenone can restore electron flow in the respiratory chain. ${ }^{67}$ However, the efficacy of coenzyme Q10 (as an electron transfer mediator or antioxidant) in treating noncoenzyme Q10-deficient patients with OXPHOS disorders remains to be proven. ${ }^{67}$ Likewise, the benefit of multiple other agents has been proclaimed in individual cases, but none has demonstrated utility in large, case-controlled studies of OXPHOS disorders. For complex I deficiency, bypass of this complex has been tried using electron transfer mediators such as succinate and triacylglycerol, or a high fat and low carbohydrate diet. ${ }^{66}$ Supplement of nicotinamide has been theorized to provide increased NADH for complex I, and vitamin precursors or cofactors (e.g., riboflavin, thiamin, niacin, and vitamin K) may boost production of certain complexes of the respiratory chain. ${ }^{66,68}$ Antioxidant use (e.g., vitamin C, vitamin E, or lipoic acid) remains popular to scavenge the free radicals that accumulate in patients with OXPHOS disorders. ${ }^{68}$ Carnitine has long been used, as patients with OXPHOS disorders may be secondarily deficient in carnitine, in an attempt to prevent toxicity of acyl-coenzyme A. ${ }^{66}$ Newer treatments include creatine monohydrate (potential alternative energy source of phosphocreatine), L-arginine (a vasodilator which may prevent stroke-like episodes inpatients with MELAS), and uridine (to replace a putative pyrimidine deficiency inpatients with oxidative phosphorylation disorders). ${ }^{66}$

\section{CONCLUSION}

The literature contains many examples of mitochondrial involvement in the presentation of seemingly diverse clinical situations. Our understanding of the interaction between the nuclear genome, i.e., gene products destined to function directly or indirectly with the mitochondrion, and the mitochondrial genome is increasing dramatically due to the growth in 'omics: genomics, proteomics, metabolomics, etc. We have attempted to integrate mitochondrial ribosomal proteins into this picture by suggesting that their expression and requirement for mitochondrial translation must be considered for possible involvement in clinical conditions. Variants in MRP genes should be studied for their association with various phenotypes or as ge- 
netic modifiers of existing known gene mutations (mt-tRNA, mt-rRNA, etc.). Initially, this will be best studied in diagnostic in vivo animal models of mitochondrial translation. Lastly, one must consider nontranslational functions for MRPs such as their potential involvement in selective protein import, chaperoning the interactions between imported and locally synthesized mitochondrial subunits during assembly of OXPHOS complexes, and translational control of mitochondrial protein synthesis.

\section{ACKNOWLEDGMENTS}

We gratefully acknowledge support by NIH/NIDCD grant RO1DC01402 (N. F.G.). J.E.S. and E.B.M. acknowledge support from the Nemours Research Programs.

\section{References}

1. DiMauro S, Schon EA. Mitochondrial respiratory-chain diseases. $N$ Engl J Med 2003;348:2656-2668.

2. O'Brien TW. Properties of human mitochondrial ribosomes. IUBMB Life 2003;55: 505-513.

3. Kenmochi N, Suzuki T, Uechi T, Magoori M, Kuniba M, Higa S et al. The human mitochondrial ribosomal protein genes: mapping of 54 genes to the chromosomes and implications for human disorders. Genomics 2001;77:65-70.

4. Taylor SW, Fahy E, Zhang B, Glenn GM, Warnock DE, Wiley S et al. Characterization of the human heart mitochondrial proteome. Nat Biotechnol 2003;21:281-286.

5. Lescuyer P, Strub JM, Luche S, Diemer H, Martinez P, Van Dorsselaer A et al. Progress in the definition of a reference human mitochondrial proteome. Proteomics 2003;3:157-167.

6. Uechi T, Tanaka T, Kenmochi N. A complete map of the human ribosomal protein genes: Assignment of 80 genes to the cytogenetic map and implications for human disorders. Genomics 2001;72:223-230.

7. O'Brien TW. Evolution of a protein-rich mitochondrial ribosome: implications for human genetic disease. Gene 2002;286:73-79.

8. Chinnery PF, Howell N, Andrews RM, Turnbull DM. Clinical mitochondrial genetics. J Med Genet 1999;36:425-436.

9. Tessa A, Vilarinho L, Casali C, Santorelli FM. MtDNA-related idiopathic dilated cardiomyopathy. Eur J Hum Genet 1999;7:847-848.

10. Degoul F, Brule H, Cepanec C, Helm M, Marsac C, Leroux J et al. Isoleucylation properties of native human mitochondrial tRNAIle and tRNAIle transcripts. Implications for cardiomyopathy-related point mutations $(4269,4317)$ in the tRNAIle gene. Hum Mol Genet 1998;7:347-354.

11. Prezant TR, Agapian JV, Bohlman MC, Bu X, Oztas S, Qiu WQ et al. Mitochondrial ribosomal RNA mutation associated with both antibiotic-induced and non-syndromic deafness. Nat Genet 1993;4:289-294.

12. Estivill X, Govea N, Barcelo E, Badenas C, Romero E, Moral L et al. Familial progressive sensorineural deafness is mainly due to the mtDNA A1555G mutation and is enhanced by treatment of aminoglycosides. Am J Hum Genet 1998;62:27-35.

13. Fischel-Ghodsian N. Mitochondrial deafness. Ear Hear 2003;24:303-313.

14. Guan MX, Fischel-Ghodsian N, Attardi G. Biochemical evidence for nuclear gene involvement in phenotype of non-syndromic deafness associated with mitochondrial 12S rRNA mutation. Hum Mol Genet 1996;5:963-971.

15. Guan MX, Fischel-Ghodsian N, Attardi G. Nuclear background determines biochemical phenotype in the deafness-associated mitochondrial $12 \mathrm{~S}$ rRNA mutation. Hum Mol Genet 2001;10:573-580.

16. Bacino C, Prezant TR, Bu X, Fournier P, Fischel-Ghodsian N. Susceptibility mutations in the mitochondrial small ribosomal RNA gene in aminoglycoside induced deafness. Pharmacogenetics 1995;5:165-172.

17. Casano RA, Johnson DF, Bykhovskaya Y, Torricelli F, Bigozzi M, Fischel-Ghodsian $\mathrm{N}$. Inherited susceptibility to aminoglycoside ototoxicity: genetic heterogeneity and clinical implications. Am J Otolaryngol 1999;20:151-156.

18. Tang HY, Hutcheson E, Neill S, Drummond-Borg M, Speer M, Alford RL. Genetic susceptibility to aminoglycoside ototoxicity: how many are at risk? Genet Med 2002; 4:336-345.

19. Sligh JE, Levy SE, Waymire KG, Allard P, Dillehay DL, Nusinowitz S et al. Maternal germ-line transmission of mutant mtDNAs from embryonic stem cell-derived chimeric mice. Proc Natl Acad Sci U S A 2000;97:14461-14466.

20. Ohkoshi N, Mizusawa H, Shiraiwa N, Shoji S, Harada K, Yoshizawa K. Superoxide dismutases of muscle in mitochondrial encephalomyopathies. Muscle Nerve 1995; 18:1265-1271.
21. Koutnikova H, Campuzano V, Foury F, Dolle P, Cazzalini O, Koenig M. Studies of human, mouse and yeast homologues indicate a mitochondrial function for frataxin. Nat Genet 1997;16:345-351.

22. Pitkanen S, Robinson BH. Mitochondrial complex I deficiency leads to increased production of superoxide radicals and induction of superoxide dismutase. J Clin Invest 1996;98:345-351.

23. Babcock M, de Silva D, Oaks R, Davis-Kaplan S, Jiralerspong S, Montermini L et al. Regulation of mitochondrial iron accumulation by Yfhlp, a putative homolog of frataxin. Science 1997;276:1709-1712.

24. Lutsenko S, Cooper MJ. Localization of the Wilson's disease protein product to mitochondria. Proc Natl Acad Sci U S A 1998;95:6004-6009.

25. Casari G, De Fusco M, Ciarmatori S, Zeviani M, Mora M, Fernandez P et al. Spastic paraplegia and OXPHOS impairment caused by mutations in paraplegin, a nuclearencoded mitochondrial metalloprotease. Cell 1998;93:973-983.

26. Isobe $\mathrm{K}$, Ito $\mathrm{S}$, Hosaka H, Iwamura $\mathrm{Y}$, Kondo H, Kagawa $\mathrm{Y}$ et al. Nuclear-recessive mutations of factors involved in mitochondrial translation are responsible for agerelated respiration deficiency of human skin fibroblasts. JBiol Chem 1998;273:46014606.

27. Barrientos A, Korr D, Barwell KJ, Sjulsen C, Gajewski CD, Manfredi G et al. MTG1 codes for a conserved protein required for mitochondrial translation. Mol Biol Cell 2003;14:2292-2302.

28. Diamond KL, Blackfan KD. Hypoplastic anemia. Am J Dis Child 1938;56:464.

29. Ball SE, McGuckin CP, Jenkins G, Gordon-Smith EC. Diamond-Blackfan anaemia in the U. K.: analysis of 80 cases from a 20-year birth cohort. Br J Haematol 1996;94: $645-653$.

30. Willig TN, Niemeyer CM, Leblanc T, Tiemann C, Robert A, Budde J et al. Identification of new prognosis factors from the clinical and epidemiologic analysis of a registry of 229 Diamond-Blackfan anemia patients. DBA group of Societe d'Hematologie et d'Immunologie pediatrique (SHIP), Gesellshaft fur Padiatrische Onkologie und Hamatologie (GPOH), and the European Society for Pediatric Hematology and Immunology (ESPHI). Pediatr Res 1999;46:553-561.

31. Bresters D, Bruin MC, Van Dijken PJ. [Congenital hypoplastic anemia in The Netherlands (1963-1989)]. Tijdschr Kindergeneeskd 1991;59:203-210.

32. Ramenghi U, Garelli E, Valtolina S, Campagnoli MF, Timeus F, Crescenzio N et al Diamond-Blackfan anaemia in the Italian population. Br J Haematol 1999;104:841848 .

33. Diamond KL, Blackfan KD. Hypoplastic anemia. Am J Dis Child 1938;56:464.

34. Alter BP. Fetal erythropoiesis in stress hematopoiesis. Exp Hematol 1979;7 Suppl 5:200-209.

35. Janov AJ, Leong T, Nathan DG, Guinan EC. Diamond-Blackfan anemia. Natural history and sequelae of treatment. Medicine (Baltimore) 1996;75:77-78.

36. Alter BP, Young NS. The Bone Marrow Failure Syndromes. In: Nathan DG and Orkin SH, eds. Nathan and Oski's Hematology of Infancy and Childhood, 5th ed. Philadelphia, PA: W.B. Saunders Company, 1998:290-298.

37. Glader BE. Diagnosis and management of red cell aplasia in children. Hematol Oncol Clin North Am 1987;1:431-447.

38. Vlachos A, Lipton JM. Bone marrow failure in children. Curr Opin Pediatr 1996;8: 33-41.

39. Gustavsson P, Willig TN, van Haeringen A, Tchernia G, Dianzani I, Donner M, Elinder G et al. Diamond-Blackfan anaemia: genetic homogeneity for a gene on chromosome 19q13 restricted to $1.8 \mathrm{Mb}$. Nat Genet 1997;16:368-371.

40. Draptchinskaia N, Gustavsson P, Andersson B, Pettersson M, Willig TN, Dianzani I et al. The gene encoding ribosomal protein S19 is mutated in Diamond-Blackfan anaemia. Nat Genet 1999;21:169-175.

41. Bommer UA, Stahl J, Henske A, Lutsch G, Bielka H. Identification of proteins of the $40 \mathrm{~S}$ ribosomal subunit involved in interaction with initiation factor eIF-2 in the quaternary initiation complex by means of monospecific antibodies. FEBS Lett 1988; 233:114-118.

42. Shrestha A, Horino K, Nishiura H, Yamamoto T. Acquired immune response as a consequence of the macrophage-dependent apoptotic cell clearance and role of the monocyte chemotactic S19 ribosomal protein dimer in this connection. Lab Invest 1999;79:1629-1642.

43. Cmejla R, Blafkova J, Stopka T, Zavadil J, Pospisilova D, Mihal V et al. Ribosomal protein S19 gene mutations in patients with diamond-blackfan anemia and identification of ribosomal protein S19 pseudogenes. Blood Cells Mol Dis 2000;26:124132.

44. Da Costa L, Willig TN, Fixler J, Mohandas N, Tchernia G. Diamond-Blackfan anemia. Curr Opin Pediatr 2001;13:10-15

45. Gazda H, Lipton JM, Willig TN, Ball S, Niemeyer CM, Tchernia G et al. Evidence for linkage of familial Diamond-Blackfan anemia to chromosome 8p23.3-p22 and for non-19q non-8p disease. Blood 2001;97:2145-2150.

46. Matthews DE, Hessler RA, Denslow ND, Edwards JS, O’Brien TW. Protein composition of the bovine mitochondrial ribosome. J Biol Chem 1982;257:87888794 . 


\section{Sylvester et al.}

47. Pietromonaco SF, Hessler RA, O'Brien TW. Evolution of proteins in mammalian cytoplasmic and mitochondrial ribosomes. J Mol Evol 1986;24:110-117.

48. Spirina O, Bykhovskaya Y, Kajava AV, O’Brien TW, Nierlich DP, Mougey EB et al. Heart-specific splice-variant of a human mitochondrial ribosomal protein (mRNA processing; tissue specific splicing). Gene 2000;261:229-234.

49. Monk D, Bentley L, Hitchins M, Myler RA, Clayton-Smith J, Ismail S et al. Chromosome 7p disruptions in Silver Russell syndrome: delineating an imprinted candidate gene region. Hum Genet 2002;111:376-387.

50. Dorr S, Midro AT, Farber C, Giannakudis J, Hansmann I. Construction of a detailed physical and transcript map of the candidate region for Russell-Silver syndrome on chromosome 17q23-q24. Genomics 2001;71:174-181.

51. Chabrol B, Sigaudy S, Paquis V, Montfort MF, Giudicelli H, Pellissier JF et al. StuveWiedemann syndrome and defects of the mitochondrial respiratory chain. Am J Med Genet 1997;72:222-226.

52. Slee JJ, Smart RD, Viljoen DL. Deletion of chromosome 13 in Moebius syndrome. J Med Genet 1991;28:413-414.

53. Seyda A, Newbold RF, Hudson TJ, Verner A, MacKay N, Winter S et al. A novel syndrome affecting multiple mitochondrial functions, located by microcell-mediated transfer to chromosome 2p14-2p13. Am J Hum Genet 2001;68:386-396.

54. Dahl HH. Getting to the nucleus of mitochondrial disorders: identification of respiratory chain-enzyme genes causing Leigh syndrome. Am J Hum Genet 1998;63: $1594-1597$.

55. Abramowicz MJ, Albuquerque-Silva J, Zanen A. Corneal dystrophy and perceptive deafness (Harboyan syndrome): CDPD1 maps to 20p13. J Med Genet 2002;39:110112.

56. Chaib H, Kaplan J, Gerber S, Vincent C, Ayadi H, Slim R, Munnich A et al. A newly identified locus for Usher syndrome type I, USH1E, maps to chromosome $21 \mathrm{q} 21$. Hum Mol Genet 1997;6:27-31.

57. Gong W, Emanuel BS, Collins J, Kim DH, Wang Z, Chen F et al. A transcription map of the DiGeorge and velo-cardio-facial syndrome minimal critical region on 22q11. Hum Mol Genet 1996;5:789-800.

58. Olson TM, Keating MT. Mapping a cardiomyopathy locus to chromosome 3p22p25. J Clin Invest 1996;97:528-532.
59. Stogbauer F, Young P, Timmerman V, Spoelders P, Ringelstein EB, Van Broeckhoven $\mathrm{C}$ et al. Refinement of the hereditary neuralgic amyotrophy (HNA) locus to chromosome 17q24-q25. Hum Genet 1997;99:685-687.

60. Vazza G, Zortea M, Boaretto F, Micaglio GF, Sartori V, Mostacciuolo ML. A new locus for autosomal recessive spastic paraplegia associated with mental retardation and distal motor neuropathy, SPG14, maps to chromosome 3q27-q28. Am J Hum Genet 2000;67:504-509.

61. Servidei S, Capon F, Spinazzola A, Mirabella M, Semprini S, De Rosa G et al. A distinctive autosomal dominant vacuolar neuromyopathy linked to 19p13. Neurology 1999;53:830-837.

62. Shoffner JM, Brown MD, Torroni A, Lott MT, Cabell MF, Mirra SS et al. Mitochondrial DNA variants observed in Alzheimer disease and Parkinson disease patients. Genomics 1993;17:171-184.

63. Hutchin T, Cortopassi G. A mitochondrial DNA clone is associated with increased risk for Alzheimer disease. Proc Natl Acad Sci U S A 1995;92:6892-6895.

64. Ballinger SW, Shoffner JM, Hedaya EV, Trounce I, Polak MA, Koontz DA et al. Maternally transmitted diabetes and deafness associated with a $10.4 \mathrm{~kb}$ mitochondrial DNA deletion. Nat Genet 1992;1:11-15.

65. Patti ME, Butte AJ, Crunkhorn S, Cusi K, Berria R, Kashyap S et al. Coordinated reduction of genes of oxidative metabolism in humans with insulin resistance and diabetes: Potential role of PGC1 and NRF1. Proc Natl Acad Sci US A 2003;100: 8466-8471

66. Mahoney DJ, Parise G, Tarnopolsky MA. Nutritional and exercise-based therapies in the treatment of mitochondrial disease. Curr Opin Clin Nutr Metab Care 2002;5: $619-629$.

67. Geromel V, Darin N, Chretien D, Benit P, DeLonlay P, Rotig A et al. Coenzyme $\mathrm{Q}(10)$ and idebenone in the therapy of respiratory chain diseases: rationale and comparative benefits. Mol Genet Metab 2002;77:21-30.

68. Marriage B, Clandinin MT, Glerum DM. Nutritional cofactor treatment in mitochondrial disorders. J Am Diet Assoc 2003;103:1029-1038.

69. Rebhan M, Chalifa-Caspi V, Prilusky J, Lancet D. GeneCards: Encyclopedia for genes, proteins and diseases. Rehovot, Israel: Weizmann Institute of Science; 1997. 